\title{
Bullying on Social Media (Facebook) in the Jordanian Society: A Study on Behaviorally and Emotionally Disturbed Youth
}

\author{
Mouna Ahmad Fares Al - Louzi
}

\begin{abstract}
The present study aimed to explore the level of electronic bullying among behaviorally and emotionally disturbed youth in Jordan. The researchers adopted a descriptive analytical approach. The sample consist from 100 behaviorally and emotionally disturbed youth. The questionnaire was developed based on literature review. The study found that level electronic bullying among behaviorally and emotionally disturbed youth in Jordan is Moderate. The study also found that there isn't any statistically significant difference between the levels of electronic bullying among behaviorally and emotionally disturbed youth in Jordan attributed to (gender, education, location). The study recommend that an awareness campaign should be conducted for members of society to avoid bullying.
\end{abstract}

Keywords: Bullying, Social Media, Facebook, Youth

DOI: $10.7176 / \mathrm{JEP} / 11-19-05$

Publication date:July $31^{\text {st }} 2020$

\section{Introduction}

People kill themselves over it cyberbullying. It's always on the news. Kids die because someone picks on them and that isn't something to joke about. I believe if it is bad enough the first time they could kill themselves even if it doesn't happen again. Well, it can't happen again and that's probably why they do it [suicide]. But really, heaps of people at our school get depressed over cyberbullying, why wouldn't you? (Larson, 15, male) This article reports on research with some Australian youth and their teachers about social media use and cyberbullying. The focus here is on adversarial peer relations online and how the school bullying policy deals with cyberbullying. The research questions for the study were as follows: What are some sociological patterns in cyberbullying among young people at school? What effect does cyberbullying have on young people's emotional wellbeing? The analysis of data in the article is theoretically framed using Bourdieu's productive notions of field, social capital, and cultural capital, representing an interpretive innovation in the sociological field of cyberbullying studies. Two important fields for the young people here are the school and the online domain of social media. Social capital refers to the effectiveness or otherwise of their social networking to shore up bonds of friendship and status in both the online and the offline field. Cultural capital refers, first, to the demonstrated capacity to operate social media and online connections successfully and, second, to the knowledge of what is currently considered "cool" in talk, attitudes, and information by their peers in both fields.

\section{Cyberbullying on Social Media}

As technology has become more advanced, cyberbullying is now able to occur from several outlets including cellular phones, Internet chat rooms, online blogs, e-mails, and instant messaging. Many college students find themselves spending countless hours using some form of digital technology. According to CTIA-The Wireless Association (2010), wireless use in the United States increased 78\% from 2005 to 2009, with 276.6 million subscribers and more than 1.36 trillion text messages. Moreover, social media sites provide an environment where victims often become targets of cyberbullies. The most common social networking sites where cyberbullying occurs are Facebook, Twitter, and Instagram. One of the most popular social media Web sites, Facebook (2010). reported over 3.5 billion Web links, news stories, blog posts, notes, and photos shared each week by its more than 350 million users. These sites are intended to provide a positive outlet for social networking and recreation. Despite this fact, individuals are victimized and most victims have no knowledge of the person or persons responsible for their acts. With the capability of cyberbullying occurring anywhere, jurisdictional laws make disciplining cyberbullies extremely difficult. School officials have had a difficult time monitoring online activities, knowing when to report this abuse to law enforcement, and distinguishing first amendment rights of freedom of expression from harassment (Shariff \& Hoff, 2007; Willard, 2007).

Cyberbullying definition and participant roles A common starting point for conceptualising cyberbullying are definitions of traditional (i.e. offline) bullying, one of the most influential ones being formulated by. The researcher described bullying based on three main criteria, including i) intention (i.e. a bully intends to inflict harm on the victim), ii) repetition (i.e. bullying acts take place repeatedly over time) and iii) a power imbalance between the bully and the victim (i.e. a more powerful bully attacks a less powerful victim). With respect to cyberbullying, a number of definitions are based on the above criteria. Opinion on the applicability of the above characteristics to cyberbullying is very much divided, and besides theoretical objections, a number of practical limitations have been observed. Firstly, while claims intention to be inherent to traditional bullying, this is much harder to ascertain in 
an online environment. Online conversations lack the signals of a face-to-face interaction like intonation, facial expressions and gestures, which makes them more ambiguous than real-life conversations. The receiver may therefore get the wrong impression that they are being offended or ridiculed. Another criterion for bullying that might not hold in online situations is the power imbalance between the bully and the victim. This can be evident in real life (e.g. the bully is taller, stronger or older than the victim).

\section{Detecting and preventing cyberbullying}

As mentioned earlier, although research on cyberbullying detection is more limited than social studies on the phenomenon, some important advances have been made in recent years. In what follows, we present a brief overview of the most important natural language processing approaches to cyber bullying detection, but we refer to the survey paper by for a more detailed overview. Although some studies have investigated the effectiveness of rule-based modelling the dominant approach to cyberbullying detection involves machine learning. Most machine learning approaches are based on supervised or semi-supervised learning The former involves the construction of a classifier based on labelled training data, whereas semi supervised approaches rely on classifiers that are built from a training corpus containing a small set of labelled and a large set of unlabelled instances. Semi-supervised methods are often used to handle data sparsity, a typical issue in cyberbullying research. As cyber bullying detection essentially involves the distinction between bullying and non-bullying posts, the problem is generally approached as a binary classification task where the positive class is represented by instances containing (textual) cyberbullying, while the negative class is devoid of bullying signals.

\section{Young People and New Media}

Young people today are often described as a "digital generation" (Buckingham, 2013, p. 1). This refers to the original claim by Tapscott (1998) that technology has changed the way they think. However, Buckingham (2013, p. 2) refutes such technological determinism, pointing out that what young people do with new media is an extension of their face-to-face social activities, such as connecting with friends, gossiping, flirting, showing off, quarreling, and so on (see Ito et al., 2009). Yet, as Papacharissi (2014) points out, "online technologies thrive on collapsing public and private boundaries" (p. 94). So private confidences offered online can suddenly be disseminated to a vast audience of peers for their amusement. Similarly, adversarial peer relations at school can easily relay into cyberspace harassment and back again into escalated conflicts at school. Similarly, peer conflict that starts on social media can extend into the face-to-face realm in the schoolyard and even get physical. We know that "young people have always devoted attention to the presentation of self. Friendships have always been made, displayed and broken" (Livingstone, 2008, p. 394). In relative terms, there have always been winners and losers in the offline peer social stakes, so it is no surprise that peer interaction sometimes erupts into bullying online just as it does offline: "Life online, like life offline, involves opportunities for enhancing relational closeness and enacting relational hostility" (Weinstein \& Selman, 2014, p. 3). Where it involves online victimization, the latter has been termed "cyberbullying" (Levy et al., 2012). An American study by Low and Espelage (2013) found that $10 \%-33 \%$ of youth aged 11-19years reported being bullied online and $15 \%$ of youth identified themselves as having conducted cyberbullying. Similarly, Li's (2006) research in Canada found that one in four junior high students had been cyberbullied. An Australian study (Hemphill \& Heerde, 2014) found 5.1\% of young people selfreported they cyberbullied, 5\% reported being bullied online only, and $9.5 \%$ reported both cyberbullying perpetration and being bullied. The effects can be serious. Each year some young people commit suicide as a result of cyber harassment (Bauman, Toomey, \& Walker, 2013). Yet, the main empirically established impacts of cyberbullying remain similar to those for face-to-face bullying. These impacts are lowered self-esteem, emotional alienation, poor school attendance, poor learning outcomes, and diminished capacity to form relationships (Englander, Mills, \& McCoy, 2009; Hutzell \& Payne, 2012; Kowalski \& Limber, 2013). Consequently, schools are very concerned to deal effectively with the impacts of peer cyberbullying, which is regarded as often worse than face-to-face bullying. They wish to identify perpetrators and sanction them accordingly. Schools therefore have discipline policies that recognize cyberbullying. Teachers are supposed to implement policy by encouraging students to report if they have been victimized online by fellow pupils. Yet in fact, school policies that recognize cyberbullying often falter at the point of effective identification of key actors and events. First, most social media interaction between young people involves peers they know offline, so it is difficult to separate offline and online harassment because they tend to reinforce each other. Second, as boyd (2010) argues, "measuring 'cyberbullying' or Internet harassment, is difficult, in part because both scholars and teens struggle to define it" (p. 107). Supporting the spirit of this claim, the research reported here found that high school students and teachers defined cyberbullying quite differently. Finally, social media technology is handled with evident generational expertise by the students, to the extent that the teachers seem to be left behind in trying to implement policy.

\section{Statement of the Problem}

Numerous local studies dealing with bullying indicated that school bullying is a growing phenomenon in recent 
times and the spread of modern means of communication. Bullying took another form: electronic bullying that does not end with the end of school hours, but bullying continues to harass the victim remotely and continuously as bullying is Electronic is a modern problem with major negative effects, both at the level of bullies themselves and their victims. Bullying and the victim during electronic bullying live longer periods of emotional distress than other forms of bullying. Hence, the problem of this study is represented in the following questions: What is the level of electronic bullying among behaviorally and emotionally disturbed youth in Jordan?

\section{The Study's Objectives and Questions}

This study aimed to explore the level of electronic bullying among behaviorally and emotionally disturbed youth in Jordan. To be specific, this study aimed to answers follwing questions:

Q.1: What is the level of electronic bullying among behaviorally and emotionally disturbed youth in Jordan?

Q.2: Is there any statistically significant difference between the levels of electronic bullying among behaviorally and emotionally disturbed youth in Jordan attributed to (gender, education, location)?

\section{The Study's Significance}

The importance of this study stems from the importance of the subject that it deals with, as it is one of the educational developments that resulted from the development of the means of communication. The importance of the study can be illustrated in its theoretical and practical dimensions as follows:

- Theoretical importance: This study provides a theoretical framework on electronic bullying that can be used to guide and guide students on the foundations of dealing with modern communications technology. It also provides facts and information about the link of electronic bullying with some emotional and behavioral disorders.

- Applied importance: This study provides a measure of electronic bullying that can be used to measure the levels of electronic bullying among students. It is also hoped that the mentors will benefit from the results of the study in guiding students to adjust some behaviors during their communication using smart phones and electronic communication methods, as the results of this study benefit the researcher in the factors of spread Cyberbullying, its causes and how to mitigate its effects.

\section{Definition of Terms}

The study's terms are defined below:

Bullying: "an aggressive, intentional act carried out by a group or individual, using electronic forms of contact, repeatedly and over time, against a victim who cannot easily defend him or herself.

Social Media: "A category of sites that is based on user participation and user-generated content. They include social networking sites like LinkedIn, Facebook, or My Space, social bookmarking sites like Del.icio.us, social news sites like Digg or Simpy, and other sites that are centered on user interaction.

\section{The Study's Limitations}

The present study was conducted in Jordanian youth only. It was conducted during the period (April- July, 2020).

\section{Previous Studies}

Cynthia Van He et al (2018) While social media offer great communication opportunities, they also increase the vulnerability of young people to threatening situations online. Recent studies report that cyberbullying constitutes a growing problem among youngsters. Successful prevention depends on the adequate detection of potentially harmful messages and the information overload on the Web requires intelligent systems to identify potential risks automatically. The focus of this paper is on automatic cyberbullying detection in social media text by modelling posts written by bullies, victims, and bystanders of online bullying. We describe the collection and finegrained annotation of a cyberbullying corpus for English and Dutch and perform a series of binary classification experiments to determine the feasibility of automatic cyberbullying detection. We make use of linear support vector machines exploiting a rich feature set and investigate which information sources contribute the most for the task. Experiments on a hold-out test set reveal promising results for the detection of cyberbullying-related posts. After optimisation of the hyperparameters, the classifier yields an F1 score of $64 \%$ and $61 \%$ for English and Dutch respectively, and considerably outperforms baseline systems.

Pam Nilan et al (2015) Cyberbullying is a relatively recent phenomenon that can have significant consequences for young people's wellbeing due to the specific technological affordances of social media. To date, research into cyberbullying has been largely quantitative; thus, it often elides the complexity of the issue. Moreover, most studies have been "top down," excluding young people's views. Our qualitative research findings suggest that young people engage in cyberbullying to accrue social benefits over peers and to manage social pressures and anxiety, while cultural conventions in gender performance see girls engage differently in cyberbullying. We conclude that cyberbullying, like offline bullying, is a socially constructed behavior that provides both pleasure 
and pain.

Richard Donegan (2017) Bullying has been engrained in American society since the country's founding. Bred from a capitalistic economy and competitive social hierarchy, bullying has remained a relevant issue through the years. Technological bullying, known today as cyberbullying, has allowed the problem to expand, become more elusive, and even harder to define. A thorough analysis of various case studies, statistical research, law cases, and news articles was conducted to understand the issue of cyberbullying and to find preventative measures that should be taken. This paper illuminates the background situation, current legal struggles, clinical implications, and potential preventative steps concerning bullying and cyberbullying alike.

We note that previous studies discussed the topic of social media in general and its related to behaviorally and emotionally of people, and a section of them also discussed the topic of Technological bullying, most studies did not link the relationship between behaviorally and emotionally disturbed and bullying on social media (facebook). so the present study is distinguished by studing the bullying on social media (facebook) in the jordanian society.

\section{Methodology}

\subsection{Approach}

The researchers adopted a descriptive analytical approach.

\subsection{Population}

The population consists from all behaviorally and emotionally disturbed in Jordan.

\subsection{Sample}

The random stratified sampling method was used. The sample consist from 100 behaviorally and emotionally disturbed youth. The sample were chosen in cooperation with psychotherapy centers. The scale was filled by the youth.. Table 1 presents the distribution of the sample.

Table 1. Distribution of the sample in accordance with gender, Education, Location.

\begin{tabular}{llll}
\hline Variable & Category & Frequency & Percent \\
\hline \multirow{3}{*}{ Gender } & Male & 71 & 71.0 \\
& Female & 29 & 29.0 \\
& Total & 100 & 100.0 \\
& Secondary & 48 & 48.0 \\
& University & 41 & 39.6 \\
\multirow{5}{*}{ Location } & Postgraduate & 11 & 11.0 \\
& Total & 100 & 100.0 \\
& City & 66 & 66.0 \\
& Village & 34 & 340 \\
& Total & 100 & 100.0 \\
\hline
\end{tabular}

\subsection{The Study's Instrument}

The researchers of the present study developed a questionnaire. The study's questionnaire was developed based on literature review. Ten statement set to measure the attitude of the study sample of behaviorally and emotionally disturbed youth towards electronic bullying. The rating categories in the latter questionnaire are: never, sometimes, neutral, often and always. The score of these categories are: 1, 2, 3, 4 and 5 respectively. The scale was filled by the sample dirctly.

\subsection{Validity of the Scale}

The validity of the scale refers to the capability of the questionnaire to measure what's intended to measure. It was measured through passing the initial version of the questionnaire to several experts from Jordanian university in order for them to assess it.

\subsection{Reliability of the Scale}

The reliability of the questionnaire was measured through calculating the Cronbach alpha coefficient value. The value of Cronbach alpha was 0.801 which is accepted.

\subsection{The Study's Variables}

The study's variables are listed below:

The independent variables: Gender, Education, Location.

The independent variable: bullying among behaviorally and emotionally disturbed youth. 
8.8 Methods and Criteria for Statistical Analysis

The SPSS program was used for analyzing the collected data. Several methods were used to analyze data statistically such as frequencies and percentages means and standard deviations Cronbach alpha coefficient value and multivariate analysis.

The following criteria were used to classify means:

1-2.49: low

2.50-3.24: moderate

3.25-4: High

\section{Results and Discussion}

9.1 First Question

Q.1: What is the level of electronic bullying among behaviorally and emotionally disturbed youth in Jordan?

Means and standard deviations are calculated. Table 2 presents these values:

Table 2. Means and standard deviations for identifying the level of electronic bullying among behaviorally and emotionally disturbed youth in Jordan

\begin{tabular}{clcccc} 
No & \multicolumn{1}{c}{ Statements } & M & S.D & Rank & Degree \\
\hline 7 & I am facing some sharp criticism on Facebook & 3.67 & 0.91 & 1 & Moderate \\
4 & I am constantly bullied on Facebook & 3.66 & 0.93 & 2 & Moderate \\
3 & My character is being offended by some people on Facebook & 3.65 & 1.11 & 3 & Moderate \\
1 & My life is commented by some Facebook friends & 3.61 & 0.94 & 4 & Moderate \\
2 & Sometimes I am despised by unknown people on Facebook & 3.59 & 1.10 & 5 & Moderate \\
6 & Facebook is an area for psychological abuse & 3.53 & 0.71 & 6 & Moderate \\
5 & Bullying through social media became apparent & 3.51 & 0.83 & 7 & Moderate \\
10 & If I am bullied on social media, my psyche is greatly affected & 3.48 & 0.51 & 8 & Moderate \\
9 & I don't like social media because of bullying & 3.47 & 0.84 & 9 & Moderate \\
8 & Bullying has affected society in recent years & 3.41 & 1.90 & 10 & Moderate \\
& Total & 3.65 & 0.81 & & Moderate
\end{tabular}

Based on Table 2, the level electronic bullying among behaviorally and emotionally disturbed youth in Jordan is Moderate. That is because the overall mean is 3.65 which is Moderate. The overall standard deviation is 0.81 . The latter statement states the following: I am facing some sharp criticism on Facebook .

This may be explained by the presence of medium levels of bullying on social media, As bullying has not become a dangerous phenomenon for all segments of society, Despite his presence and exposure of people to him Especially those who have satisfactory behavioral or psychological problems.

The results of the study are consistent with Pam Nilan et al (2015) who reported that young people engage in cyberbullying to accrue social benefits over peers and to manage social pressures.

\subsection{Second Question}

Q.2: Is there any statistically significant difference between the levels of electronic bullying among behaviorally and emotionally disturbed youth in Jordan attributed to (gender, education, location)?

Means and standard deviations are calculated. Table 3 presents these values:

Table 3. Means and standard deviations for identifying the levels of electronic bullying among behaviorally and emotionally disturbed youth in Jordan attributed to (gender, education, location)

\begin{tabular}{lllll}
\hline Variable & Category & No & S.D & M \\
\hline \multirow{2}{*}{ Gender } & Male & 71 & 3.63 & 1.11 \\
\cline { 2 - 5 } & Female & 29 & 3.65 & 0.94 \\
\hline \multirow{3}{*}{ Education } & Secondary & 48 & 3.57 & 1.10 \\
\cline { 2 - 5 } & University & 41 & 3.56 & 0.71 \\
\cline { 2 - 5 } & Postgraduate & 11 & 3.51 & 0.83 \\
\hline \multirow{2}{*}{ Location } & City & 66 & 3.61 & 0.51 \\
\cline { 2 - 5 } & village & 34 & 3.58 & 0.84 \\
\hline
\end{tabular}

Based on Table 3, it appears that there are differences between the levels of electronic bullying among behaviorally and emotionally disturbed youth in Jordan attributed to (gender, education, location). To identify whether these differences are statistically significant or not at the statistical significance level of $a=0.05$, the multivariate analysis of variance was conducted. The results of the latter analysis are presented below through Table 4 below: 
Table 4. The results of the multivariate analysis of variance

\begin{tabular}{llllll}
\hline Source & Sum of Squares & df & Mean Square & F & Sig. * \\
\hline Gender & .575 & 1 & 0.575 & 0.525 & 0.333 \\
Education & .047 & 1 & 0.047 & 0.133 & 0.757 \\
Location & 7.041 & 1 & 7.041 & 13.711 & 0.090 \\
Error & 83.543 & 97 & 0.400 & & \\
Total & 1655.920 & 100 & & & \\
\hline
\end{tabular}

Based on Table 4, it was found that there isn't any statistically significant difference between the levels of electronic bullying among behaviorally and emotionally disturbed youth in Jordan attributed to (gender, education, location). That is because the significance values of gender and school stage are $0.333,0.757$ and 0.090 respectively.

This may be explained by the fact that bullying is not limited to one category and not another. Bullying is exposed to males and females, also, bullying is not limited to a specific region or educational level.

\section{Recommendations}

The researchers recommend the following:

- An awareness campaign should be conducted for members of society to avoid bullying.

- Conducting more applied research on the impact of bullying on society.

\section{References}

1. Livingstone S, Haddon L, Go“rzig A, O' lafsson K. Risks and safety on the internet: The perspective of European children. Initial Findings. London: EU Kids Online; 2010.

2. Tokunaga RS. Following You Home from School: A Critical Review and Synthesis of Research on Cyberbullying Victimization. Computers in Human Behavior. 2010; 26(3):277-287. https://doi.org/10. 1016/j.chb.2009.11.014

3. Mckenna KY, Bargh JA. Plan 9 From Cyberspace: The Implications of the Internet for Personality and Social Psychology. Personality \& Social Psychology Review. 1999; 4(1):57-75. https://doi.org/10.1207/ S15327957PSPR0401

4. Gross EF, Juvonen J, Gable SL. Internet Use and Well-Being in Adolescence. Journal of Social Issues. 2002; 58(1):75-90. https://doi.org/10.1111/1540-4560.00249

5. Juvonen J, Gross EF. Extending the school grounds?-Bullying experiences in cyberspace. Journal of School Health. 2008; 78(9):496-505. https://doi.org/10.1111/j.1746-1561.2008.00335.x PMID: 18786042

6. Hinduja S, Patchin JW. Bullies Move Beyond the Schoolyard: A Preliminary Look at Cyberbullying. Youth Violence And Juvenile Justice. 2006; 4(2):148-169. https://doi.org/10.1177/1541204006286288

7. Van Cleemput K, Bastiaensens S, Vandebosch H, Poels K, Deboutte G, DeSmet A, et al. Zes jaar onderzoek naar cyberpesten in Vlaanderen, Belgie" en daarbuiten: een overzicht van de bevindingen. (Six years of research on cyberbullying in Flanders, Belgium and beyond: an overview of the findings.) (White Paper). University of Antwerp \& Ghent University; 2013.

8. Livingstone S, Haddon L, Vincent J, Giovanna M, O' lafsson K. Net Children Go Mobile: The Uk report; 2014. Available from: http://netchildrengomobile.eu/reports. [Accessed 30th March 2018].

9. O’Moore M, Kirkham C. Self-esteem and its relationship to bullying behaviour. Aggressive Behavior. 2001; 27(4):269-283. https://doi.org/10.1002/ab.1010

10. Fekkes M, Pijpers FIM, Fredriks AM, Vogels T, Verloove-Vanhorick SP. Do Bullied Children Get Ill, or Do Ill Children Get Bullied? A Prospective Cohort Study on the Relationship Between Bullying and HealthRelated Symptoms. Pediatrics. 2006; 117(5):1568-1574. https://doi.org/10.1542/peds.2005- 0187 PMID: 16651310

11. Cowie H. Cyberbullying and its impact on young people's emotional health and well-being. The Psychiatrist. 2013; 37(5):167-170. https://doi.org/10.1192/pb.bp.112.040840

12. Price M, Dalgleish J. Cyberbullying: Experiences, Impacts and Coping Strategies as Described by Australian Young People. Youth Studies Australia. 2010; 29(2):51-59.

13. Van Royen K, Poels K, Daelemans W, Vandebosch H. Automatic monitoring of cyberbullying on social networking sites: From technological feasibility to desirability. Telematics and Informatics. 2014;

14. Cortes C, Vapnik V. Support-Vector Networks. Machine Learning. 1995; 20(3):273-297. https://doi.org/ 10.1007/BF00994018

15. Chang CC, Lin CJ. LIBSVM: A Library for Support Vector Machines. ACM Transactions on Intelligent Systems and Technology (TIST). 2011; 2(3):27:1-27:27.

16. Dalla Pozza V, Di Pietro A, Morel S, Emma P. Cyberbullying among Young People. European Parliament; 2016.

17. Olweus D. Bullying at School: What We Know and What We Can Do. 2nd ed. Wiley; 1993. 18. Smith PK, 
Mahdavi J, Carvalho M, Fisher S, Russell S, Tippett N. Cyberbullying: its nature and impact in secondary school pupils. Journal of Child Psychology and Psychiatry. 2008; 49(4):376-385. https:// doi.org/10.1111/j.1469-7610.2007.01846.x PMID: 18363945

19. Internet Marketing Press Releases Glossary: https://www.lazworld.com/glossary

20. Vandebosch H, Van Cleemput K. Defining cyberbullying: a qualitative research into the perceptions of youngsters. Cyberpsychology and behavior: the impact of the Internet, multimedia and virtual reality on behavior and society. 2008; 11(4):499-503. https://doi.org/10.1089/cpb.2007.0042

21. Vandebosch H, Van Cleemput K. Cyberbullying among youngsters: profiles of bullies and victims. New Media \& Society. 2009; 11(8):1349-1371. https://doi.org/10.1177/1461444809341263

22. Dooley JJ, Cross D. Cyberbullying versus face-to-face bullying: A review of the similarities and differences. Journal of Psychology. 2009; 217:182-188.

23. Slonje R, Smith PK, Frise'n A. The Nature of Cyberbullying, and Strategies for Prevention. Compututers in Human Behavior. 2013; 29(1):26-32.https://doi.org/10.1016/j.chb.2012.05.024

24. Van Hee C, Verhoeven B, Lefever E, De Pauw G, Daelemans W, Hoste V. Guidelines for the FineGrained Analysis of Cyberbullying, version 1.0. LT3, Language and Translation Technology Team- Ghent University; 2015. LT3 15-01. 